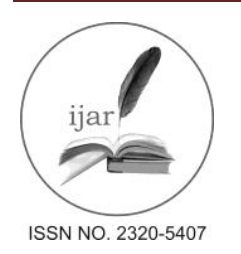

Journal homepage: http://www.journalijar.com

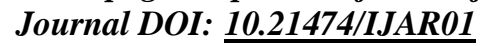

INTERNATIONAL JOURNAL

OF ADVANCED RESEARCH

RESEARCH ARTICLE

\title{
MODIFIED TECHNIQUE OF TRANS-NASAL TRANS-SPHENOIDAL MICRO-DECOMPRESSION FOR PITUITARY ADENOMAS-AN EXPERIENCE.
}

\author{
Ab Queem Khan, Manzoor A Tali, Yasir Bashir, Mohammad Akbar Shah*, Nusrat Bashir4, Imtiyaz A \\ Naqash, Abdul Rashid Bhat*.
}

\section{Manuscript Info}

Manuscript History:

Received: 15 May 2016

Final Accepted: 13 June 2016

Published Online: July 2016

Key words:

Pituitary, adenoma, decompression..

*Corresponding Author

Mohammad Akbar Shah.

\begin{abstract}
Background:- Weighing 0.6 grams the pituitary has unassuming regulatory functions on human body and the tumors of pituitary explain the pervasive might of this tiny structure.

Patients and methods:- we carried out a prospective comparative study on two patient groups of thirty patients each. One of the groups underwent conventional technique for tumor decompression with xylocaine-adrenaline nasal mucosa infiltration and the other one underwent a modified technique of tumor decompression with normal saline infiltration. In addition we used gelatin foam in empty sella in modified technique in place of fat as is done in conventional surgical procedure. The results of two groups were compared. The patients with tumor infiltration into the sinuses and major vessels were excluded from the study.

Results and conclusion:- Modified surgical technique is safe and very effective in terms of in perioperative hemodynamics, blood loss, surgical field and post-operative MRI interpretation.
\end{abstract}

Copy Right, IJAR, 2016,. All rights reserved.

\section{Introduction:-}

Most accounts of the history of pituitary surgery began with an operation done by Paul a British surgeon for an acromegalic patient in 1892 via a subtemporal decompression.Later Horsely operated a series of pituitary tumors using temporal and subfrontal approaches and reported it in 1906. Major technical and conceptual advances were made from Viena and Schloffer in 1907 was first to employ a lateral rhinotomy type surgery for tumor removal ${ }^{1}$. Later Guoit ${ }^{2}$ and Hardly ${ }^{3,4}$ established technical and conceptual modification of these procedures which forms the basis of present day transsphenoidal surgery.

\section{Patients and methods:-}

This study was carried out at our superspeciality hospital for a period of two years. It was a prospective comparative study where in two groups of thirty patient each were compared in terms of perioperative hemodynamics, intraoperative bleeding, surgical field and post operative imaging interpretation. All the patients were subjected to baseline investigations, pituitary hormone analysis and pituitary imaging. Patients with functional pituitary tumorswith out mass effect and infiltration into major vessels an base of skull were excluded from the study. The study group patients underwent modified surgical technique with use of normal saline in place of xylocaineadrenaline and gel foam was placed into empty sella in place of fat as is done conventionally. The anesthetist was blind to the drugs infiltrated into nasal mucosa. Hemodynamics, amount of bleeding and surgery timeswere recorded in all the patients. Post operatively at 3 months MRI Brain was done to compare sellar cavities. All the data was compiled and analysed statistically by descriptive statistical analysis by using SPSS and Microsoft excel softwares.

\section{Results:-}

The patients included in our study ranged from 18-62 years in control group and 18-70 years in case study group. The total number of males were $10(33.3 \%)$ and females were $(66.7 \%)$ in control group. The total number of males 
were $13(43.3 \%)$ and females were $17(56.7 \%)$ in case study group. The mean age in control group was $40.4 \pm 13.2$ and $43.9 \pm 13.3$ in case study group.

Pituitary tumors were divided into non-functional and functional adenomas. The NFPT were 15(50\%) in control group and $16(53 \%)$ in case study group. The most common tumor was somatotropinoma in both the groups.

Preoperative MRI findings showed 25(83.3\%) patients had macroadenoma in control group and case study group each. Tumors were graded according to Modified Hardy 's grade. Majorty of patients had grade 3 tumors in both the groups.

Hemodynamic changes were seen in $63.3 \%$ of patients in control group viz $10 \%$ in case study group. The need for antihypertensive medication was $60 \%$ in control group viz $10 \%$ in case study group. There were statistically significant differences in heart rate and mean arterial blood pressures in the two groups.

The sellar graft and second incision was used in all 30(100\%) patients of control group and no patient of case study group. In this respect case study group was less time consuming and cosmetically better.

Most of the patients in our study had normal course in both the groups. Transient diabetesinspidus was the most common complication seen in $20 \%$ of patients in control group and $26 \%$ of case group.

Postoperatively MRI interpretation was easy in case group as compared to control group of patients in terms of differentiating hematoma, residual tumor and implanted graft.

\section{Discussion:-}

The pituitary adenomas are the most common tumors in the sellar region and makes upto $10-15 \%$ of all the intracranial tumors. The major clinical presentations are endocrine disturbances, features of raised intracranial tension and visual disorder. The objective of removing pituitary adenoma is not limited to relieving the compression of the optic nerve and optic chiasma by the tumor but rather includes total resection of the tumor and amelioration or recovering of the pituitary function. The age range of patients in our study group and control group were 18-62 and 18-70 years respectively. The age groups were nearly comparable to those seen by R-X Cheng where age ranged from 13-69 years ${ }^{5}$. Their patients were diagnosed at an earlier age and ours were little delayed because majority of our patients were from rural background.

In our study maximum of our patients were in nonfunctional pituitary tumors $15(50 \%)$ in case study group and 16(53.3\%) in control group. The most common pituitary tumor in both case and control group was somatotropninoma $9(30 \%)$ in case group and 7(23\%) in control group of patients. The results for nonfunctional pituitary tumors and functional pituitary tumors were comparable to that seen by Amir R Dehdashtiin $2008^{6}$.

The Hardy grade 3 tumor percentage was the most common grade seen in our study and the results were comparable to that seen by Xue-FeiShou MD ${ }^{7}$.

The control group hemodynamic changes were present in $63.3 \%$ patients whereas it was only seen in $10 \%$ of patients in study group. The difference is statistically significant with $\mathrm{p}$ value of $<0.05$. As a result of more hemodynamic changes in control group there was more blood loss and poor operative field visibility. The study conducted by Pasternak J et al 2004, Chelliah Y R et al 2002,Keegan MT et al 2006,found that during prepration, the mucosal surfaces of the nose are infiltrated with local anesthesia and epinephrine solution to reduce bleeding and facilitate dissection. The addition of lidocaine to epinephrine increases the arrhythmogenic threshold dose of epinephrine when compared with epinephrine in saline injection. Injection may be associated with dysrhythmias and hypertension. This hypertension may be significant and myocardial ischemia and cardiac troponin increase has been reported in patients without coronary artery disease. Patients taking beta adrenergic blockers may develop dangerously high blood pressures secondary to unopposed alpha effects of epinephrine. IV therapy with phentolamine or direct vasodilator therapy may be necessary; however increasing the patients depth of anesthesia may prove adequate. If an endoscopic approach is planned infiltration of mucosal surfaces may be necessary and the administration of topical vasoconstrictor may prove adequate. , $^{8,10,11,12,13,14 . .}$.

As is evident from above discussion our findings were consistent with the international data. 
In our study in control group sellar graft(fat) was used in all the patients and second surgical incision was needed in all the patients where as no sellar graft was used in the reconstruction of sella in case group and for the closure of sella bone piece and gelatin foam was used. In 3 patients in case group there was intraoperative CSF leak and in addition to bone piece gel foam was used. The most common complication was diabetes inspidus which was seen in $20 \%$ in control group and $8 \%$ in case group. This DI was transient which recovered by 3-4 days of surgery. Meningitis and epistaxis was seen in one patient each.

Post operative MRI interpretation( image 1 and 2) in differentiating hematoma, residual tumor, implanted heterologous material and sellar graft was done in all patient after 3 months postoperatively.

The postoperative MRI interpretation(image 1 and 2) was easy in majority of patients in case study group and it was difficult to interpret in patients in control group which was statistically significant.

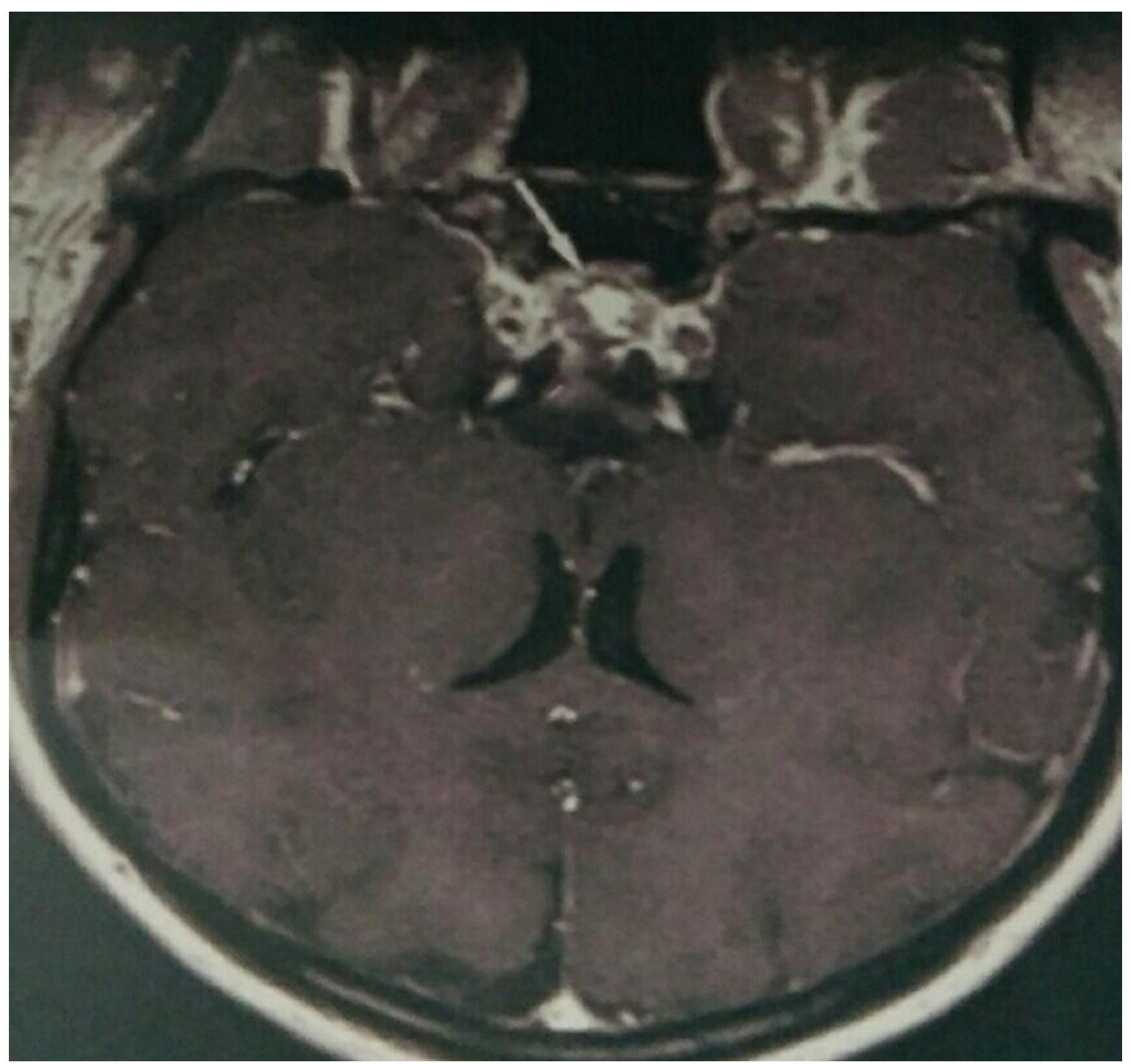

Fig.1:- Post operative MRI interpretation showingSellar graft(fat) used in control group 


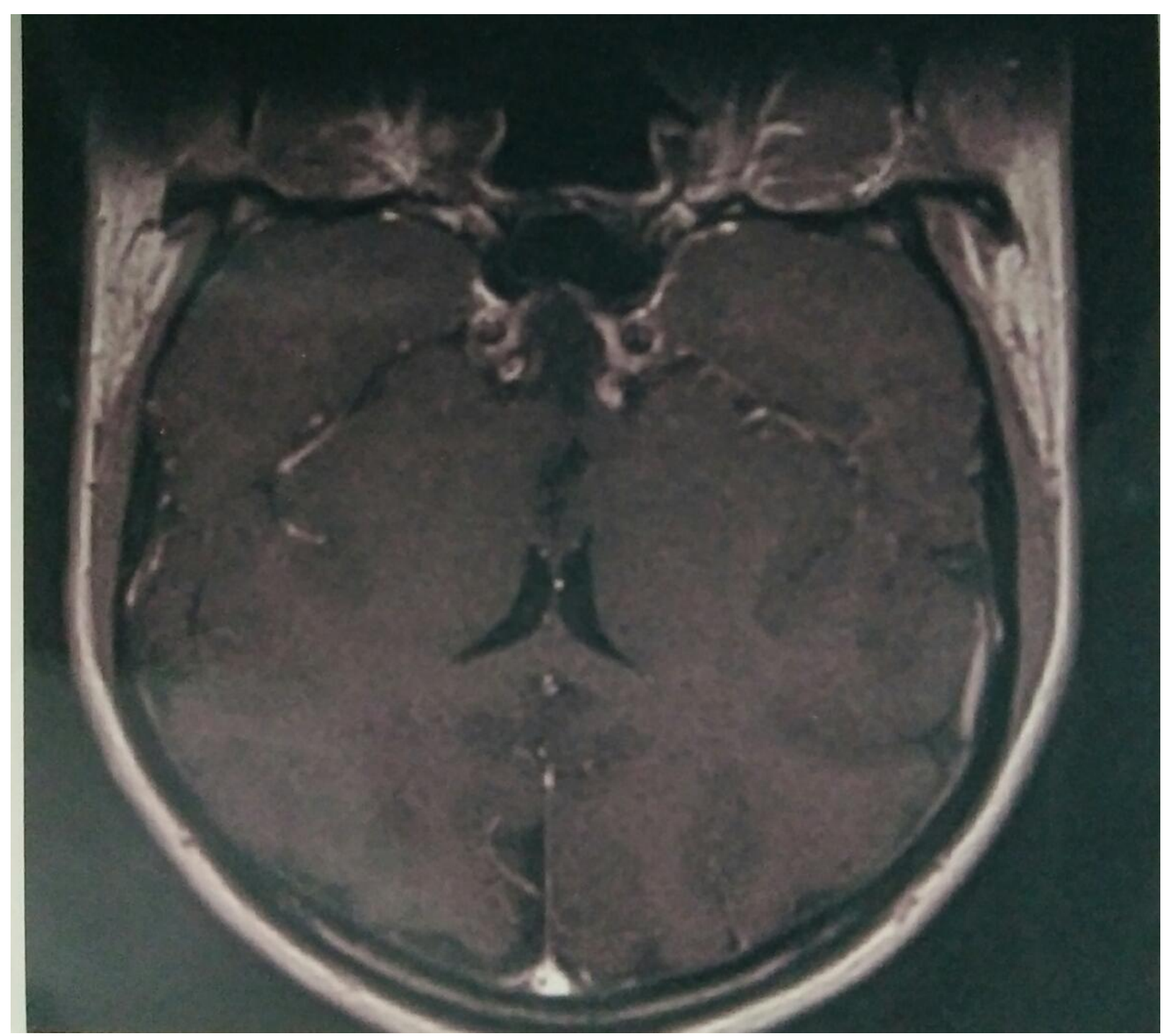

Fig.2:- The postoperative MRI interpretationin case group where as no sellar graft was used in the reconstruction of sella and for the closure of sella bone piece and gelatin foam was used.

Rolf W. Seilar et al 2000 conducted a study where patients underwent surgery for pituitary adenomas, cysts and craniophyrangiomas. Sellar reconstruction was performed with a commercially available synthetic absorbable patch composed of polyglactin 910/poly-p-dioxanone, gelatin foam and fibrin glue. The patch is essentially reabsorbed in 2-3 months and is replaced by fibrocollagentissue.because of progressive resorption of the substitute material the interpretation of post operative MRI studies was not significantly hindered. ${ }^{15}$

Similar study results were also reported by Sonnenburg et al in $2003^{16}$ and Joanna et al in $2010^{17}$.

Conclusion:Modified surgical technique is safe and very effective in terms of in perioperative hemodynamics, blood loss, surgical field and post-operative MRI interpretation. 


\section{Bibliography:-}

1. Schloffer H:Erfolgreiche Operation einesHypophysentumors auf nasalemwege.wienklinwochenshr 20:621624,1907.

2. Guiot G, Arfel G BrionS,etal:AdenomesHypophysaires. Paris:Masson,1958.

3. Hardy J. Transsphenoidalhypophysectomy. J Neurosurg 1971;34:582-94.

4. Hardy J:Lexerese des adenomeshypophysiares par voietranssphenoidale. Union Medicale du Canada 91:933$945,1962$.

5. R-X Cheng,H-L Tian, W-W Gao and Z-Q Li, Transsphenoidal Microsurgery for Functioning Pituitary Adenomas. Journal of International Medical Research 2011 39:1985-1993.

6. Dehdashti AR, Ganna A, karabatsou K, Gentili F, Pure endoscopic endonasal approach for pituitary adenomas: early surgical results in 200 patients and comparision with previous microsurgical series. Neurosurgery. 2008 May;62(5):1006-15;discussion 1015-7.

7. Xue-FeiShou, MD. Shi-qi Li et al .Treatment of pituitary adenoma with transsphenoidal approach. Neurosurgery 2005:56:249-256.

8. ChelliahMY,Manninen PH. Hazars of epinephrine in transphenoidalpituitary surgery. J NeurosurgAnesthesiol2002;14:43-6.

9. Edward C. Nemergut, MD, Aaron s et al Perioperative Management of Patients Undergoing Trans-sphenoidal Pituitary surgery, AnesthAnalg 2005;101;1170-81.

10. Goranovic T MillicM ,Parazagder D, Avdagic E Haemodynamic effects and the visibility of the surgical field after lidocaine infiltration during septoplasty under general anesthesia. Period boil 111:267-272.

11. Keegan MT, Atkinson JL, Kasperbauer JL, Lanier WL. Exaggerated hemodynamic responses to nasal injection and awakening from anesthesia in a cushingoid patient having transsphenoidalhypophysectomy. $\mathrm{J}$ NeurosurgAnesthesiol 2000;12:225-9.

12. M Lim a, D Williams et al Anesthesia for pituitary surgery Journal of the Islamic republic of Iran, Vol 27, No. 4, Nov 2013,pp. 186-194.

13. Pasternak J, AtkisonJ,KasperbauerJ,Lanier W. Hemodynamic responses to epinephrine containing local anesthetic injection andemergence from general anesthesia in transsphenoidalhypophysectomy patients. J NeurosurgAnesthesiol 2004;16:189-95.

14. Sukhminderjit Singh Bajwa and SukhwinderKaurBajwa; Anesthesia and Intensive care implications for pituitary surgery; Recent trends and advancements, Indian J Endocrinol Metab.2011 September ;15(suppl3): S224-S232.

15. Roif W. Seilar,MD, Mariani M.D. Sellar Reconstruction with resorbableVicryl Patches, Gelatin Glue in Transsphenoidal surgery. A 10 year experience with 376 patients. J Neurosurg 2000 Nov;93(5):762-5

16. Sonnenburg RE, White D, Ewend MG, Senior B, Sellar reconstruction: is it necessary ?Am J Rhinol. 2003 NovDec;17(6):343-6.

17. Joanna Bladowska, GrazynaBednarek-Tupikowka, MRI image characteristics of materials implanted at sellar region after transsphenoidal resection of pituitary tumorsPol J Radiol, 2010;75(2):46-54. 